\title{
Gender Determination Using Mandibular Angle Measurement in Iranian Adult Graphics in a Dental Center
}

\author{
Maryam Vasheghani Farahani ${ }^{1}$, Ramin Mashhadi Ismaeeli ${ }^{2}$, Iraj Mirzaii-Dizgah (iD ${ }^{3}$ and Mahdi \\ Isazadeh (iD) ${ }^{4}{ }^{*}$ \\ ${ }^{1}$ Department of Forensic Medicine and Clinical Toxicology, Faculty of Medicine, AJA University of Medical Sciences, Tehran, Iran \\ ${ }^{2}$ Student Research Committee, Faculty of Dentistery, AJA University of Medical Sciences, Tehran, Iran \\ ${ }^{3}$ Department of Physiology, AJA University of Medical Sciences, Tehran, Iran \\ ${ }^{4}$ Student Research Committee, Faculty of Medicine, AJA University of Medical Sciences, Tehran, Iran \\ "Corresponding author: Student Research Committee, Faculty of Medicine, AJA University of Medical Sciences, Tehran, Iran. Email: mahdiisazadeh@yahoo.com
}

Received 2021 March 14; Revised 2021 September 13; Accepted 2021 September 15.

\section{Abstract}

Background: The mandibular bone is affected by age, metabolic activity, and hormonal changes.

Objectives: This study aimed to determine the sex determination using the mandibular angle in the adult population of Iran.

Methods: This cross-sectional study enrolled 149 patients ( 73 men and 76 women) referred to the 600 Army Dental Center in 2016. Graphics were obtained from cephalogram and panorex using a Soredex digital device and Pack software to measure mandibular angles.

Results: The mean mandibular angle was $122.19 \pm 3.89$ in men and $124.72 \pm 3.24$ in women, with a significant difference based on the independent $t$ test $(\mathrm{P}<0.05)$.

Conclusions: It seems that the mandibular angle is higher in women than in men.

Keywords: Mandibular Angle, Gender Determination, Iranian

\section{Background}

Gender recognition is an important issue in forensics and anthropology. Gender differences in the bony pelvis and skull are well defined. After these two bones, it is the mandibular bone in humans that helps us identify age, sex, and race (1). The mandibular bone, like other bones in the body, is affected by age, metabolic activity, and hormonal changes (2). The mandibular angle is actually the angle between the posterior border of the Ramos mandible and the lower border of the mandibular bone (3). The mandibular bone is the largest and strongest bone in the face with a horizontally curved, convex forward structure with two broad rami, which climbs upwards at the end of the structure. The coronoid and condyloid appendages of the mandibular bone are considered suitable for study, as this bone is the most durable facial skeleton and retains its shape better than do other bones. Differences in the mandible between different sexes may be due to relative differences in the development of the musculoskeletal system, especially the masticatory muscles attached to the mandible $(4,5)$.

Radiographs are a good tool for identification in forensic medicine. The accuracy of measurements in radiography is based on the quality of radiography. This device provides the ability to view the entire structure of the mandible (6). Considering what was said about the importance of the mandibular bone in sex determination, this study was performed to investigate sex determination using mandibular angle measurement in the graphics of Iranian adults referred to the 600 Army Dental Center in 2016.

\section{Methods}

In a cross-sectional study, 73 men and 76 women aged over 18 years were enrolled. Patients were excluded from the study if they did not have an identity document, or had trauma to the mandible, congenital malformations, bone disease, or a history of maxillofacial surgery. Also, if the stereotype lacked the desired quality for evaluation for any reason, it was excluded from this study. Pack software 
was used to measure the mandibular angles (the angle between the intersection of the posterior side of the ascending horn and the lower side of the mandible) in all Panorex graphs on the right (Figure 1). Men and women were divided into three age groups: $18-34,35-49$, and $\leq 50$ years. The amount of radiation was $60-63 \mathrm{kV}$ in women and 66 - $70 \mathrm{kV}$ in men, which was irradiated for 18 seconds, with maximum radiation of $80 \mathrm{kV}$.

The data were analyzed by ROC, Two-way ANOVA, and Bonferroni post hoc test using SPSS 22 software. The statistical significance level in the present study was considered less than 0.05 .

The present study with the ethics code of IR.AJAUMS.REC.1399.223 was approved by the Ethics Committee of the Army University of Medical Sciences.

\section{Results}

The mean mandibular angle was significantly higher in women than in men (Table 1). However, there was no significant difference in the mean mandibular angle between age groups. Mandibular angle had a significant cutoff point for sex differentiation (Table 2).

\section{Discussion}

Gender determination is one of the most important pieces of information that can be obtained from bones (7). It has been demonstrated that humans differ from each other in size and proportion and that these variances can affect the metric assessment of sex. In the present study, the mandibular angle was significantly higher in women. It is in agreement with the other studies (8-11). However, some reports contradict our results $(12,13)$. This difference may be because they performed their study on completely toothless or toothless elderly patients in the posterior region. The mandibular angle increased non-significantly with age, which is in agreement with other reports (14). This result may be due to that muscle function preserves the bone at the point where the muscle joins the bone. Therefore, the connection of the internal pterygoid muscle and the master leads to the preservation of the gonial angle region. With age, the diet becomes softer, and the chewing force decreases; thus, the size of the gonial angle increases as getting older and bone resorption in the area. The mandibular angle was much higher in the present study than in the study by Akhlaghi et al. (15), which examined the mandibular angle in 12 to 19-year-old Iranian population, and this indicates an increase in the mandibular angle with age. Our measurements in this study confirm this subject.

In the present study, unlike most studies in Iran that examined the mandibular bone in corpses, the mandibular bone of living individuals was examined. It should be noted that in the present study, in order to investigate the characteristics of the mandibular bone, an all-digital device and pack software were used, which are the other distinguishing features of the present study compared to other studies conducted in Iran. It is suggested that a longterm study be performed on a larger statistical population. Factors such as tooth or tooth loss, malocclusions, and chewing patterns should also be considered as variables, as these can also affect outcomes.

\subsection{Conclusions}

It may be concluded that the radiomorphometric index measured in this study, i.e., the mandibular angle, may predict gender, but this is not the case for age and cannot be used as an accurate and practical tool in estimating the age of individuals.

\section{Footnotes}

Authors' Contribution: All authors contributed equally to the writing of the article.

Conflict of Interests: The authors declare no conflict of interest.

Ethical Approval: The present study with the ethics code of IR.AJAUMS.REC.1399.223 was approved by the Ethics Committee of the Army University of Medical Sciences.

Funding/Support: No found or support was received. Informed Consent: It was not declared by the authors. 

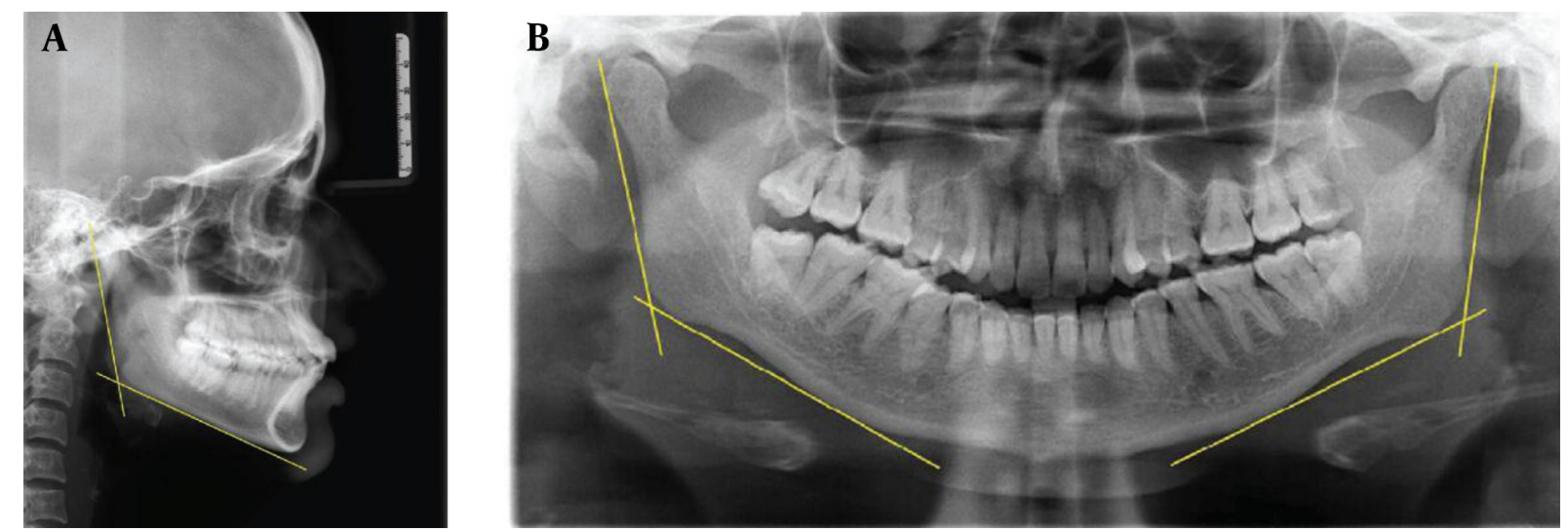

Figure 1. Mandibular angles in (A) cephalogram and (B) panorex graphics.

\begin{tabular}{|c|c|c|c|c|c|}
\hline & $18-34, y$ & $35-49, y$ & Above 50,y & All Ages & PValue $^{\mathrm{b}}$ \\
\hline Male & $121.8 \pm 0.6$ & $122.4 \pm 0.9$ & $123.4 \pm 0.6$ & $122.2 \pm 0.5$ & 0.498 \\
\hline Female & $124.3 \pm 0.5$ & $124.6 \pm 0.7$ & $126.3 \pm 0.8$ & $124.7 \pm 0.4$ & 0.122 \\
\hline Pvalue & $\mathrm{P}<0.05$ & $\mathrm{P}<0.05$ & $\mathrm{P}<0.05$ & $\mathrm{P}<0.05$ & \\
\hline
\end{tabular}

${ }^{\mathrm{a}}$ Data are expressed as Mean \pm SEM and analyzed by Two-Way ANOVA and Bonferroni post hoc test.

${ }^{\mathrm{b}} \mathrm{P}<0.05$ was considered significant.
.

\begin{tabular}{lcccc}
\hline Table 2. Cutoff Point of Mandibular Angle and Mandibular Foramen Diameter (Three Directions) in Males and Females & \\
\hline Age Group & Cutoff Point (Degree) & AUC & P Value & Sensitivity (\%) \\
\hline Mandibular angle & 123.1 & 0.758 & 0.000 & 74 \\
\hline
\end{tabular}

\section{References}

1. Kumar M, Lokanadham S. Sex determination \& morphometric parameters of human mandible. Int J Res Med Sci. 2013;1(2):93-6. doi: 10.5455/2320-6012.ijrms20130511.

2. Taleb NSA, Beshlawy ME. Mandibular ramus and gonial angle measurements as predictors of sex and age in an Egyptian population sample: A digital panoramic study. J Forensic Res. 2015;6(5):1-7.

3. Solow B. The pattern of craniofacial associations: A morphological and methodological correlation and factor analysis study on young male adults. Acta Odontol Scand.1966;24:123-35.

4. Johna S. Gray's anatomy: The anatomical basis of clinical practice Elsevier / Churchill Livingstone, 2005, ISBN 0-443-06676-0. World J Surg. 2006;30(8):1624-5. doi:10.1007/s00268-006-0109-2.

5. Ongkana N, Sudwan P. Gender difference in Thai mandibles using metric analysis. Chiang Mai Med J. 2009;48(2):43-8.

6. Chandra A, Singh A, Badni M, Jaiswal R, Agnihotri A. Determination of sex by radiographic analysis of mental foramen in North Indian population.J Forensic Dent Sci.2013;5(1):52-5. doi:10.4103/0975-1475.114556. [PubMed: 23960416]. [PubMed Central: PMC3746474].

7. Ramadan SU, Turkmen N, Dolgun NA, Gokharman D, Menezes RG, Kacar M, et al. Sex determination from measurements of the sternum and fourth rib using multislice computed tomography of the chest. Forensic Sci Int. 2010;197(1-3):120 e1-5. doi: 10.1016/j.forsciint.2009.12.049. [PubMed: 20083365].
8. Tafakhori Z, Mostafazadeh G, Fathollahi MS. A study on the association of mandible anatomy with age and gender in panoramic radiography of patients referred to Rafsanjan dental school clinic. J Dent Med. 2017;29(4):253-61.

9. Casey DM, Emrich LJ. Changes in the mandibular angle in the edentulous state. J Prosthet Dent. 1988;59(3):373-80. doi: 10.1016/00223913(88)90193-X.

10. Joo JK, Lim YJ, Kwon HB, Ahn SJ. Panoramic radiographic evaluation of the mandibular morphological changes in elderly dentate and edentulous subjects. Acta Odontol Scand. 2013;71(2):357-62. doi: 10.3109/00016357.2012.690446. [PubMed: 22774938].

11. Huumonen S, Sipila K, Haikola B, Tapio M, Soderholm AL, RemesLyly $\mathrm{T}$, et al. Influence of edentulousness on gonial angle, ramus and condylar height. J Oral Rehabil. 2010;37(1):34-8. doi: 10.1111/j.13652842.2009.02022.x. [PubMed: 19912483].

12. Ceylan G, Yaníkoglu N, Yílmaz AB, Ceylan Y. Changes in the mandibular angle in the dentulous and edentulous states. $J$ Prosthet Dent. 1998;80(6):680-4. doi: 10.1016/s0022-3913(98)70055-1.

13. Raustia AM, Salonen MA. Gonial angles and condylar and ramus height of the mandible in complete denture wearers-a panoramic radiograph study. J Oral Rehabil. 1997;24(7):512-6. doi: 10.1046/j.13652842.1997.00532.x. [PubMed: 9250838].

14. Bhardwaj D, Kumar JS, Mohan V. Radiographic evaluation of mandible to predict the gender and age. J Clin Diagn Res. 
2014;8(10):ZC66-9. doi: 10.7860/JCDR/2014/9497.5045. [PubMed: 25478451]. [PubMed Central: PMC4253269].

15. Akhlaghi M, Vasigh S, Khalighi Z, Yousefinejad V. The value of mandible measurements in gender prediction for the Iranian adult population. Aust J Forensic Sci. 2013;46(2):127-35. doi: 10.1080/00450618.2013.807358. 